\title{
Big challenges: obesity and type 2 diabetes in children and adolescents
}

\author{
Jun-Fen $\mathrm{Fu}^{1}$ \\ Published online: 10 August 2019 \\ (c) Children's Hospital, Zhejiang University School of Medicine 2019
}

Childhood obesity has emerged as an important public health problem not only in developed countries but in many developing countries [1, 2]. As we know, the increasing prevalence of childhood obesity is associated with the grooving increase of the incidence of adult diseases including type 2 diabetes mellitus, nonalcoholic fatty liver disease and other disease, which dramatically threaten public health. In this month's issue of the World Journal of Pediatrics, Zeitler [3] and Chiavaroli et al. [4] sound alarm again that the prevalence of overweight/obese children in New Zealand and youth-onset type 2 diabetes in the USA is markedly higher than before. Philip S Zeitler reviewed the recent results and implications of the treatment options for Type 2 Diabetes in Adolescents and Youth (TODAY) study and the Restoring Insulin Secretion (RISE) study [3]. Chiavaroli et al. [4] revealed that obesity is a major public health concern in New Zealand; and the prevalence of overweight and obese children and adolescents in New Zealand is markedly high, with a greater impact on particular ethnicities and those of lower socioeconomic status. A previous meta-analysis has shown that the prevalence of obesity among Chinese children and adolescents increased from $7.5 \%$ in $2006-2010$ to $10.4 \%$ in 2009-2014 [5]. Xu et al. [6] found that the Chinese pediatric T2D population had serious lipid metabolism disorder, with the high levels of total triglycerides, total cholesterol, and low-density lipoprotein and the low high-density lipoprotein level. And a stepwise deterioration trend was found in beta-cell function among Chinese pediatric patients with obesity, prediabetes and T2D.

Obese children are at increased risk for abnormal cardiacvscular complications [7]. In addition to cardiovascular complications such as hypertension vascular dysfunction, we also need to pay attention to further complications of obese

Jun-Fen Fu

fjf68@zju.edu.cn

1 Department of Endocrinology, Children's Hospital, Zhejiang University School of Medicine, 3333 Binsheng Road, Hangzhou 310052, China children, such as precocious puberty, especially in obese girls [8, 9]. Childhood obesity is in consequence of complex factors such as the environment change, genetic variation, and ecological effects. Up to date, the exact mechanism of obesity has still not been completely explored. Zhao et al. [10] designed a meta-analysis study including 26 studies found that FTO SNPs were significantly related to obesity in Chinese population. For environmental factors, but also intestinal microbiome seems to play a role in the in the development and its further complications of obesity. The pro-inflammatory and immunomodulating effect of symbiosis is possible triggers of the development of insulin resistance and diabetes. Therefore, some animal model studies showed that early interventions, such as maternal weight, delivery mode, or the feeding type, seem to be important to influence optimal shaping and development of the gut microbiome. Górowska-Kowolik et al. [11] also suggests that interventions aiming at the microbiome may become new opportunities in the prevention and treatment of obesity. And McLean et al. [12] also reviewed maternal smoking on the infant gut microbiota and its association with child overweight. Maternal smoking has a solidified relation with adverse child health outcomes; and new evidences reveal that maternal smoking and household tobacco exposure on the infant gut microbiota. Child overweight and obesity likely originates from an aberrant gut microbiota in early life. Except these factors, recent studies revealed that taking oral antibiotics during childhood has been linked with an increased risk of childhood obesity. In this issue, Kelly et al. [13] reported their analysis results of 8186 children and their parents from the infant cohort of the Irish National Longitudinal Study of Children. They found that number of antibiotic courses may be an important factor in any link between early antibiotic exposure and subsequent childhood obesity.

To tackle the progressing problem of increased prevalence of obesity and diabetes in children, many interventions including diet, increase in physical activity and behavioral modifications have been proposed either separately or 
combined for preventing and treatment of obesity. Psaltopoulou et al. in their systematic review concluded that the combination of enhanced physical activity and improved nutrition emerged as apromising intervention in the fight against childhood/adolescent obesity [14].

In summary, obesity and diabetes not only increase the risk of chronic diseases, but also increase the social and economic burden. It is a big challenge to clarify the real mechanism of obesity and find effective ways to control childhood obesity and diabetes. We recommend that clinical medicine and basic research should focus on the mechanism, prevention, diagnosis and treatment of this serious disease.

Author contributions JFF is the sole author of this editorial, and is the Editor of this special issue.

Funding None.

\section{Compliance with ethical standards}

Conflict of interest No financial or nonfinancial benefits have been received or will be received from any party related directly or indirectly to the subject of this article.

\section{References}

1. Kumar S, Kelly AS. Review of childhood obesity: from epidemiology, etiology, and comorbidities to clinical assessment and treatment. Mayo Clin Proc. 2017;92:251-65.

2. Santas F, Santas G. Prevalence of pre-school children for overweight/obesity in Turkey. World J Pediatr. 2018;14:77-83.

3. Zeitler PS. Progress in understanding youth-onset type 2 diabetes in the United States: recent lessons from clinical trials. World J Pediatr. 2019;15:315-321.
4. Chiavaroli V, Gibbins JD, Cutfield WS, Derraik JGB. Childhood obesity in New Zealand. World J Pediatr. 2019;15:322-31.

5. He F, Liu J. Prevalence of obesity among primary students from 2009 to 2014 in China: an update meta-analysis. Int J Clin Exp Med. 2014;7:5348-52.

6. Xu ZR, Zhang MY, Ni JW, Cheng RQ, Zheng ZQ, Xi L, Luo FH. Clinical characteristics and beta-cell function of Chinese children and adolescents with type 2 diabetes from 2009 to 2018 . World J Pediatr. 2019;15:405-11.

7. Metwalley KA, Farghaly HS, Sherief T. Plasma adrenomedullin level in children with obesity: relationship to left ventricular function. World J Pediatr. 2018;14:84-91.

8. Li W, Liu Q, Deng X, Chen Y, Liu S, Story M. Association between obesity and puberty timing: a systematic review and meta-analysis. Int J Environ Res Public Health. 2017. https://doi. org/10.3390/ijerph14101266.

9. Hong Y, Maessen SE, Dong G, Huang K, Wu W, Liang L, et al. Associations between maternal age at menarche and anthropometric and metabolic parameters in the adolescent offspring. Clin Endocrinol (Oxf). 2019;90:702-10.

10. Zhao NN, Dong GP, Wu W, Wang JL, Ullah R, Fu JF. FTO gene polymorphisms and obesity risk in Chinese population: a metaanalysis. World J Pediatr. 2019;15:382-89.

11. Górowska-Kowolik K, Chobot A. The role of gut micorbiome in obesity and diabetes. World J Pediatr. 2019;15:332-40.

12. Mclean C, Jun S, Kozyrskyj A. Impact of maternal smoking on the infant gut microbiota and itsassociation with child overweight: a scoping review. World J Pediatr. 2019;15:341-49.

13. Kelly D, Kelly A, O'Dowd T, Hayes CB. Antibiotic use in early childhood and risk of obesity: longitudinal analysis of a national cohort. World J Pediatr. 2019;15:390-97.

14. Psaltopoulou T, Tzanninis S, Ntanasis-Stathopoulos I, Panotopoulos G, Kostopoulou M, Tzanninis I, et al. Prevention and treatment of childhood and adolescent obesity: a systematic review of meta-analyses. World J Pediatr. 2019. https://doi.org/10.1007/ s12519-019-00266-y.

Publisher's Note Springer Nature remains neutral with regard to jurisdictional claims in published maps and institutional affiliations. 